\title{
TESTING FLEXIBLE GRIPPERS FOR GEOMETRIC AND SURFACE GRASPING CONFORMITY IN RECONFIGURABLE ASSEMBLY SYSTEMS
}

\author{
C.I. Basson ${ }^{1 * \#}$, G. Bright ${ }^{1} \&$ A.J. Walker ${ }^{1}$
}

\section{ARTICLE INFO}

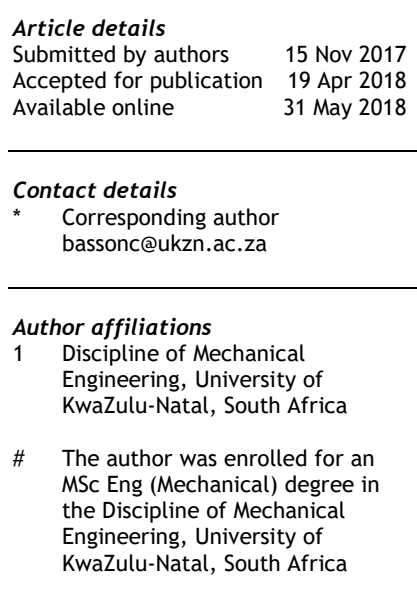

DOI

http://dx.doi.org/10.7166/29-1-1874
The ongoing development in manufacturing technology facilitates flexibility in production and faces challenges of product handling. Flexibility was required in the form of adaptable grippers for robotic arms in pick-and-place procedures for reconfigurable assembly systems. A conceptual system was designed and tested according to the surface geometric conformity of grasped objects. The system proposed was a biologically inspired Fin Ray Effect $^{\circledR}$ gripper. Grasping occurs due to the deformation of the rib structure of the appendage. The appendages were simulated for conformity by means of a finite element analysis, and performance was analysed by means of a physical sample mass test and a force test.

\section{OPSOMMING}

Die deurlopende ontwikkeling in vervaardigingstegnologie fasiliteer buigsaamheid in produksie en word blootgestel aan uitdagings aan met betrekking tot produkhantering. Buigsaamheid word vereis in die vorm van aanpasbare robot gryp gereedskap vir robotarms in optel-en-plaas prosedures vir herkonfigureerbare monteringstelsels. 'n Konseptuele stelsel is ontwerp en getoets aan die hand van die oppervlak meetkundige gelykvormigheid van gegrepe voorwerpe. Die voorgestelde stelsel was 'n biologies geïnspireerde Fin Ray Effect ${ }^{\circledR}$ gryper. Gryp vind plaas as gevolg van die vervorming van die ribstruktuur van die ledemaat. Die ledemaat is gesimuleer vir ooreenstemming deur middel van 'n eindige element analise, en verrigting is geanaliseer deur middel van 'n fisiese monster massa toets en 'n krag toets.

High production rate capabilities are required in reconfigurable manufacturing systems, which are essential in the advancement of Industry 4.0. Reconfigurable assembly systems have been implemented in modern manufacturing systems to satisfy stakeholders' needs for functionality and high-capacity production response demands [1]. Pick-and-place procedures for assembly require the efficient grasping operation of a robotic arm and end-effector collaboration. A closed-loop robotic system integration was expressed as a conceptual model for a pick-and-place procedure. The system required should involve automation for higher repeatability, increased operational production, adaptive gripping characteristics, varied mass handling, and improved material handling [2]. The specifications should be met to improve the efficiency of the system.

A review of the literature presented a wide range of possible gripping techniques for flexible grasping methods. Agile gripping eliminates time consumption when interchanging fixtures for specific tasks. Research has shown that nature proved to be inventive about effective grasping, and corresponds with managing the challenges of material handling for reconfigurable assembly lines. Biologically inspired grippers have the potential to be incorporated into highly capable robotic systems. The flexible systems should aid the following recommendations for technological development and industrial actions: performance development and assembly measure, greater integration of 
'intelligent' robotic fixturing, methodology development of human/robot collaboration, industrial gripper and sensor integration, human capability integration for autonomous robotic systems, path planning development for robotic arms, guidance of robotic hand through teaching processes, external support systems for robot system applications, combined perception systems and tactile sensing of grippers, and force control improvement for assembly systems [3].

Festo ${ }^{\circledR}$ has developed a number of biologically inspired grippers. The FlexShapeGripper ${ }^{\circledR}$ worked on the principle of a chameleon tongue [4]. Grasping by means of static surface pressure on the surface of the material, the FlexShapeGripper ${ }^{\circledR}$ proved to have excellent conformity. An alternative gripper designed by Festo ${ }^{\circledR}$ was the MultiChoiceGripper ${ }^{\circledR}$, based on the conformity mechanisms of the Fin Ray Effect ${ }^{\circledR}$ [5]. A gripper system from Empire Robotics ${ }^{\circledR}$ called Versaball ${ }^{\circledR}$ incorporated the gripping action of granular jamming [6]. Robotiq ${ }^{\circledR}$ had also designed a gripper system based on the articulation of the human hand called the AdaptiveGripper ${ }^{\circledR}$ [7]. A conceptual design was created, based on the Fin Ray Effect ${ }^{\circledR}$, with respect to the TIHRA ${ }^{\circledR}$ gripper [8] and the MultiChoiceGripper ${ }^{\circledR}$ illustrated in Figure 1. The exotic grippers described here have the potential to be implemented as flexible gripper systems to increase efficiency capabilities in production.
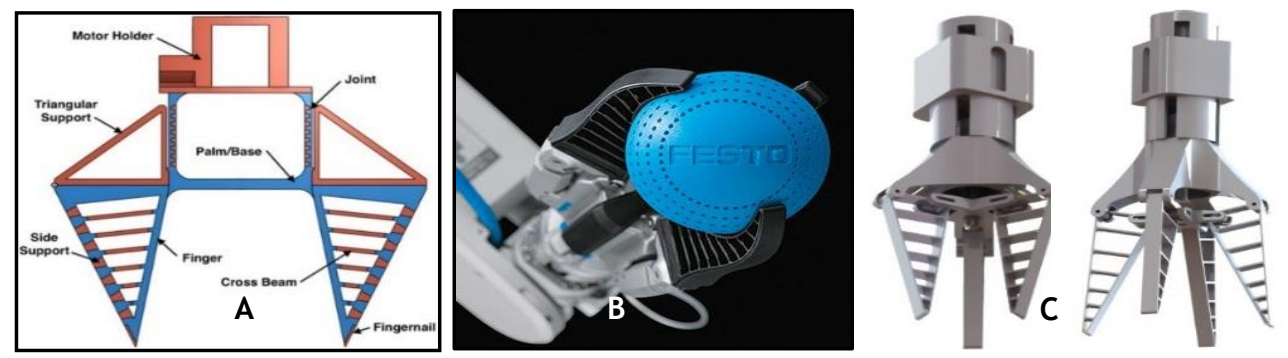

Figure 1: A) TIHRA gripper ${ }^{\circledR}$ [8]. B) MultiChoiceGripper ${ }^{\circledR}$ [5]. C) Proposed three-finger and fourfinger grippers

\section{SPECIFICATIONS FOR FLEXIBLE GRIPPING FROM THE LITERATURE}

\subsection{ISO specifications}

The design gripper system should meet the requirements specified by the ISO 14539 standard, and be followed as closely as possible. The requirements presented by the ISO were effectively incomplete with regard to the specific procedure of testing. Quantitative requirements for gripper systems were not presented in the ISO specifications. The requirements were described as follows:

- $\quad$ The gripper to be developed should follow four grip states: A gripped state, a semi-gripped state, a laid state, and a free state.

- The gripping motion of the end-effector should consider the following conformity criteria: the degrees of freedom of the grasped object excluding friction forces, form closure grasping of 0 1 degrees of freedom excluding friction forces, form closure grasping of larger than 1 degree of freedom excluding consideration of friction force, external grasping of objects, and internal grasping of objects

- $\quad$ Forces have to be considered in terms of static and dynamic loading: Contact forces with respect to the contact point, contact line and contact plane with respect to the forces exerted from the fingers, and manipulating forces are considered to be the vector sum of all the exerted forces on the object.

- The following grasping stability criteria should be considered: The grasping stability of the initial state of the gripper pose should be restored after a disturbance force is applied, and the grasping stability of the contact grasp between the object and gripper should be restored after slippage.

- $\quad$ The intelligence of the gripper system in terms of feedback control should be considered: Object presence detection of verification and confirmation of successful gripping and releasing, finger positioning sensing in terms of overall object size and specified finger movement control, grasp force sensing relating to surface sensitivity of objects and higher stability grasps, external force sensing of the object weight, integrity of contact surfaces and object handling control, 
and slip detections with regard to avoidance of handling of heavy objects and unstable gripping states.

- Specifications relating to the repeatability of robotic position control have been extracted from ISO 9283:1998 [9] and used as the basis for repeatability for gripping: The movement and object gripping of the objects should be 98 per cent repeatable, and the accuracy for repeatability should be measured with at least 10 measurements.

\subsection{Dynamic force loading}

Dynamic force loading was interpreted in terms of a force versus time grasp. The graph depicts force properties across a movement in the time domain of the manipulation. The force properties are detected in terms of the gripping performance and the criteria illustrated in Figure 2. The grip strength measurements were related to the grip fatigue of human hands over time, when grip force was measured [10]. A comparison of the grip strength of robotic grippers with human hands was established to serve as a comparable model.

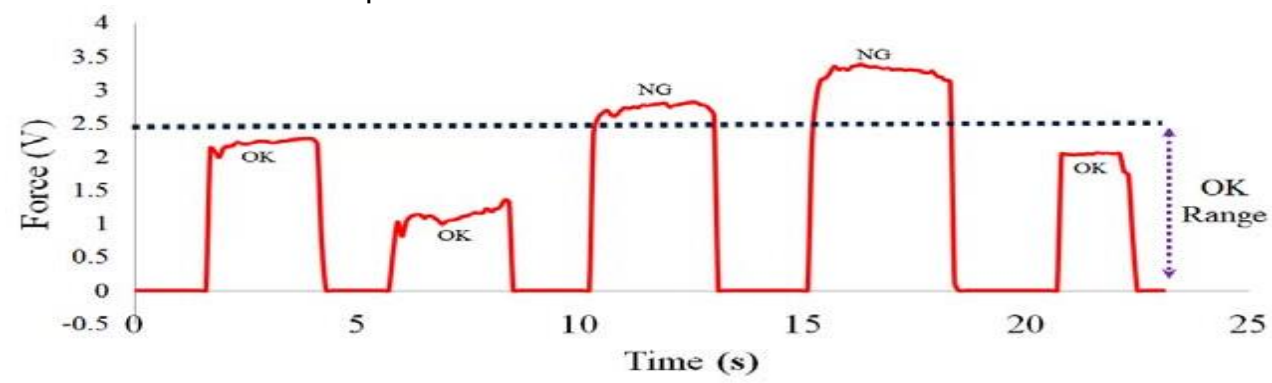

Figure 2: Gripping performance in terms of a force versus time graph [10]

\section{CONCEPTUAL DESIGN}

\subsection{Design layout}

The flexible gripping system was described as an integral arrangement that formed part of a closedloop robotic system applicable to RMS [11]. The gripper system was planned according to the functionality of an end-effector framework, as shown in Figure 3. The system required an actuation input to manipulate the fingers. The gripper system followed a gripping procedure that encompassed the following: preparation for contact, establishing contact, fixturing and retention of the object, and releasing of the object at the correct position. The output of the mechanical system required efficient handling and correct grasping of the object. The grasping criteria were measured in terms of deflection of the appendages with regards to force handling capabilities of the fingers. The specifications for the gripper system procedure were generated by making use of ISO standard guidelines [12]. A typical gripping system consists of a robotic tool or end-effector, a control unit, and a robotic arm [13]. The mechanical system design of the flexible gripper system, illustrated in Figure 4, compromised a skeletal design, an actuation subsystem, robotic arm investigation, sensory system implementation, and a control system architecture.

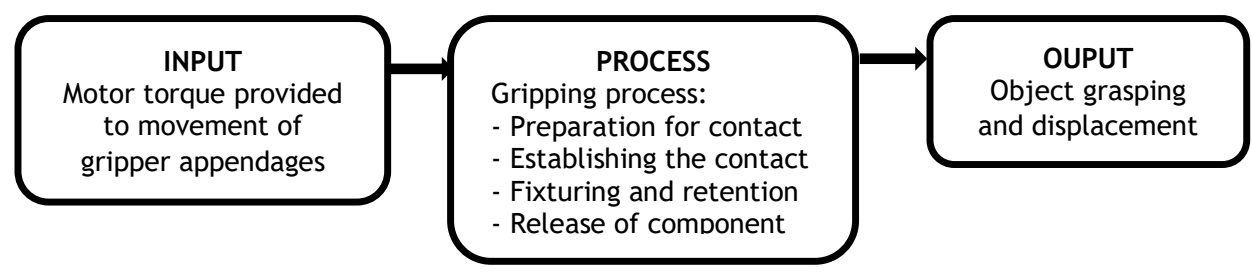

Figure 3: Gripper mechanical system procedure 


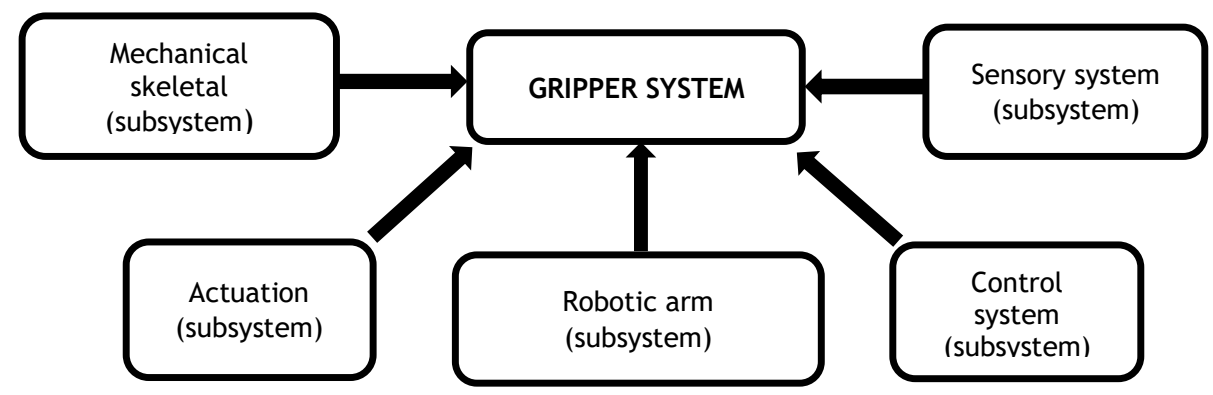

Figure 4: Gripper mechanical system outline

\subsection{Fin Ray Effect ${ }^{\circledR}$}

The gripper concept selected was based on the conformity mechanism that was itself based on the deflection of fish fin ribs. The biologically inspired gripping occurrence was explained by Kniese of EvoLogics $^{\circledR}$, who discovered the Fin Ray Effect ${ }^{\circledR}$ [14]. The appendage for the Fin Ray Effect ${ }^{\circledR}$ module $^{\circ}$ consists of a V-shaped wall structure, containing a parallel rib structure in the shape of an A-frame. Conformity of the appendage occurs as a force is applied to the wall structure. The tip of the Vshape geometry tends to envelop the disturbance force, as illustrated in Figure 5 . The unloaded structure is shown in A; the loaded structure is shown in B. The result of the shape adaption increases the surface friction contact with the object, which resembles the force. Additionally, the object is restricted from moving as a result.
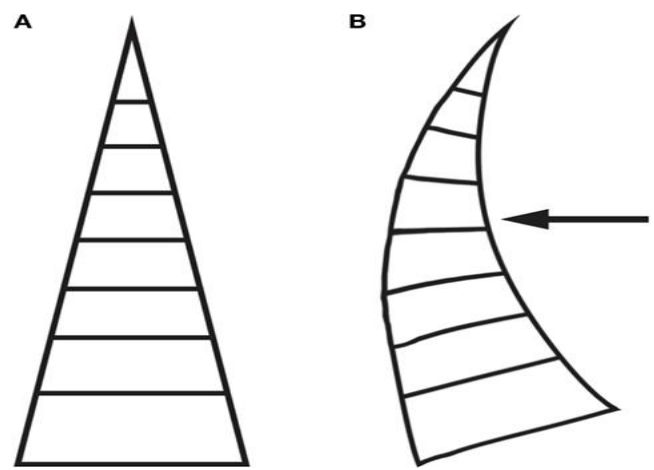

Figure 5: Mechanism of the Fin Ray Effect $^{\circledR}[14]$

\section{SIMULATION FOR CONFORMITY}

\subsection{Materials selection}

The materials were selected to enable $3 \mathrm{D}$ printing of components. The materials chosen for the simulation were acrylonitrile butadiene styrene (ABS) plastic and nylon. The reason for the choice of those materials was the high mechanical properties of printed components. The printed components were made from ABS; nevertheless, both nylon and ABS were simulated to compare the property attributes. The differences in grasping deflection and stress criteria were demonstrated in the comparison of the two selected materials. The material properties are described in Table 1. Care had to be taken when designing for 3D-printing material. The melting point had to be taken into account, the accuracy of the hole had to be considered, and the shrinkage factored had to be kept in mind [15].

Table 1: Material selection for appendage

\begin{tabular}{|l|c|c|}
\hline Material & ABS plastic & Nylon \\
\hline Elastic modulus [GPa] & 2 & 1 \\
\hline Poisson's ratio [-] & 0.4 & 0.3 \\
\hline Yield stress [MPa] & 45 & 60 \\
\hline Print temperature $\left[{ }^{\circ} \mathrm{C}\right]$ & $220-260$ & $235-260$ \\
\hline
\end{tabular}




\subsection{Rib structure configurations}

The variation in the design of the rib structures of the gripper appendages consisted of geometric variations on the parallel Fin Ray Effect ${ }^{\circledR}$ rib configuration, as shown in Figure 6 . The rib structures were designed according to the flexible and conformity properties required for effective shape grasping of objects. Geometry 1 illustrates the traditional rib configuration in the Fin Ray Effect ${ }^{\circledR}$ design. Geometry 2 shows an adapted version of the traditional structure, in which the ribs are slanted at specific angles. Geometry 3 possesses curved ribs, and has a parallel configuration similar to that of Geometry 1. Geometry 4 portrays comparable attributes related to Geometry 2 and Geometry 3, but the ribs are slanted and curved.
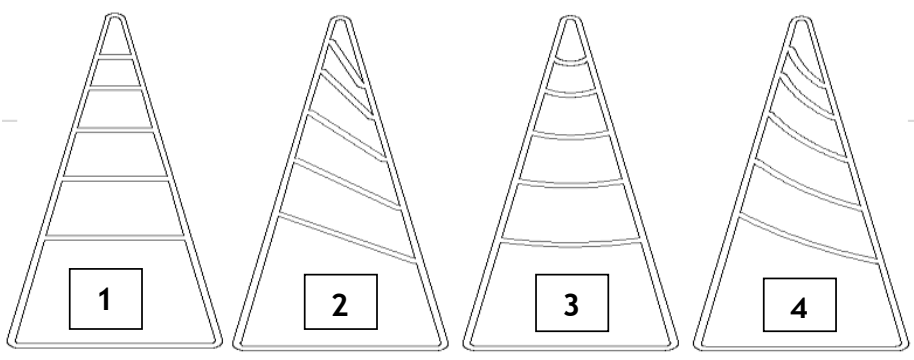

Figure 6: Rib structure design for appendages

The rib structure properties are described in Table 2 . The rib units are placed at a $180^{\circ}$ orientation from each other in the parallel alignment. Curved structures change accordingly as the V-shape of the wall structure changes to attain concentricity. Additionally, the slanted structures follow angled degree increments accordingly to the $\mathrm{V}$-shaped wall angle change. The rib structures proposed were used as a conceptual rib structure design for the simulation in testing the conformity changes of the appendage in terms of deflection and stress criteria.

Table 2: Rib orientation geometry

\begin{tabular}{|l|l|}
\hline Geometry & \multicolumn{1}{|c|}{ Rib orientation } \\
\hline $\mathbf{1}$ & Parallel $\left(180^{\circ}\right)$ \\
\hline $\mathbf{2}$ & Slanted from the bottom $\left(49.3^{\circ}, 41.6^{\circ}, 32.5^{\circ}, 21.6^{\circ}, 11.4^{\circ}\right)$ \\
\hline $\mathbf{3}$ & $\begin{array}{l}\text { Curved from the bottom }(\mathrm{r} 58.48[\mathrm{~mm}], \mathrm{r} 33[\mathrm{~mm}], \mathrm{r} 17.6[\mathrm{~mm}], \mathrm{r} 8.2[\mathrm{~mm}], \\
\mathrm{r} 3.7[\mathrm{~mm}])\end{array}$ \\
\hline $\mathbf{4}$ & $\begin{array}{l}\text { Curved from bottom }(\mathrm{r} 77.3[\mathrm{~mm}], \mathrm{r} 55.9[\mathrm{~mm}], \mathrm{r} 39.6[\mathrm{~mm}], \mathrm{r} 29.9[\mathrm{~mm}], \mathrm{r} 25.3[\mathrm{~mm}]) \\
\text { and slanted from bottom }\left(60.6^{\circ}, 54.8^{\circ}, 48.3^{\circ}, 39.8^{\circ}, 31.21^{\circ}\right)\end{array}$ \\
\hline
\end{tabular}

\subsection{Simulation preparation}

The simulation was executed using the Siemens $N{ }^{\circledR}$ software package. A finite element analysis was performed to determine the deflection of the appendage structure. The simulation enabled the conception of a potential rib structure for effective conformity in grippers. As a product of the analysis, the result was used and rib geometry shapes were selected for the gripper design.

The appendage structure was designed on SolidWorks ${ }^{\circledR}$, a computer-aided drawing (CAD) software package. The Parasolid models were imported into the simulation package illustrated in Figure 7. A force of $10 \mathrm{~N}$ was applied to the contact surface of the appendage wall in the form of a distributed load. The magnitude of the load $\mathrm{P}$ presents the minimum designed holding capacity of the gripper as $1 \mathrm{~kg}$. The contact area created was $15 \mathrm{~mm}$ in length and $25 \mathrm{~mm}$ from the end point of the V-shape of the structure. The mesh of the model was made to be $1 \mathrm{~mm}$ grid size. The material was selected with nylon and $A B S$ plastic properties for both simulation procedures. A fixed boundary condition was applied to area $\mathrm{C}$, which resembles the hinged connection on the gripper assembly unit. 


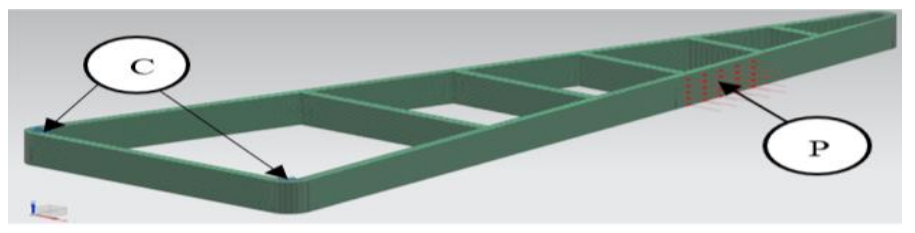

Figure 7: Constraints and loads applied to Geometry 1

A number of considerations were kept in mind for the simulation and design of the rib fingers. The post-simulation procedure required simulation convergence. The simulation's built-in software package produced an equation convergence graph, and verified that all calculated values and variables had been executed. The rib thickness adjoining the wall structure had to be kept in mind, as the deflection results would be affected. The attachment of the ribs to the V-shaped wall should be connected and have the same thickness at the joining surface for all ribs and the geometric structure. The geometry was manipulated by using fillet features in the CAD package.

\subsection{Simulation results}

The displacement of the designed appendages simulation results is represented in Figure 8 . Geometry 1 was treated as a reference for conformity because Geometry 1 represented the traditional Fin Ray ${ }^{\circledR}$ construct. The deflection in Geometry 2 increased by 14 percent compared with the reference geometry as a result of the slanted rib structure. Geometry 3 showed a slight increase of one per cent in the deflection criteria. Geometry 4 had an 11 per cent increase in deflection from the reference model. The simulation models showed that the manipulated rib structures had effects on the deflection and conformity properties of the appendage.

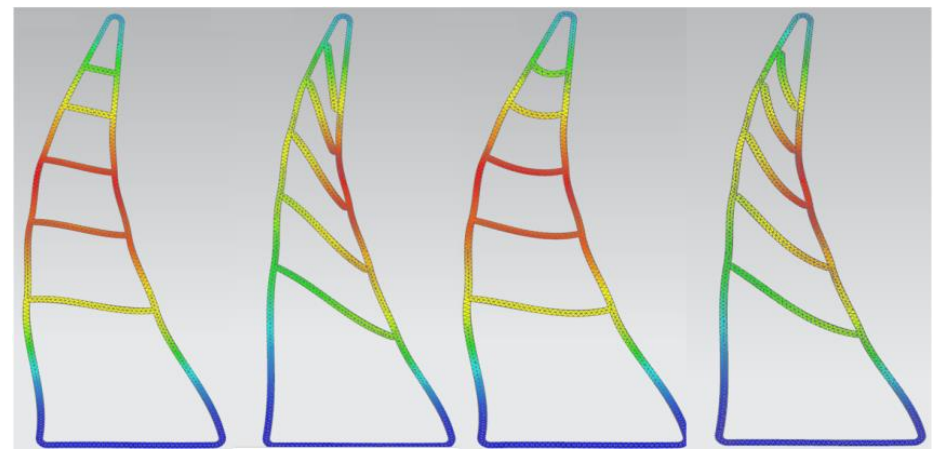

Figure 8: Displacements of geometry 1, 2, 3 and 4, from left to right (see online version for colour)

The simulation results for ABS plastic and nylon are described in Table 3 and Table 4 respectively. The stress distribution for both materials was constant due to the fact that the specific material selected had a minimal effect on stress, and the same force was applied throughout. Changes in deflection of the appendages were observed.

Table 3: Tabulated results for ABS plastic

\begin{tabular}{|l|l|l|l|l|}
\hline & Deflection & Stress & Deflection $\Delta \%$ & Stress $\Delta \%$ \\
\hline $\mathbf{1}$ & $2.027 \mathrm{~mm}$ & $14.90 \mathrm{MPa}$ & Reference & Reference \\
\hline $\mathbf{2}$ & $2.317 \mathrm{~mm}$ & $19.27 \mathrm{MPa}$ & 14.3 & 29.3 \\
\hline $\mathbf{3}$ & $2.052 \mathrm{~mm}$ & $15.28 \mathrm{MPa}$ & 1.2 & 2.6 \\
\hline $\mathbf{4}$ & $2.248 \mathrm{~mm}$ & $19.68 \mathrm{MPa}$ & 10.9 & 32.1 \\
\hline
\end{tabular}

Table 4: Tabulated results for nylon

\begin{tabular}{|l|l|l|l|l|}
\hline & Deflection & Stress & Deflection $\Delta \%$ & Stress $\Delta \%$ \\
\hline $\mathbf{1}$ & $1.013 \mathrm{~mm}$ & $14.90 \mathrm{MPa}$ & Reference & Reference \\
\hline $\mathbf{2}$ & $1.159 \mathrm{~mm}$ & $19.27 \mathrm{MPa}$ & 14.4 & 29.3 \\
\hline $\mathbf{3}$ & $1.026 \mathrm{~mm}$ & $15.28 \mathrm{MPa}$ & 1.3 & 2.6 \\
\hline $\mathbf{4}$ & $1.124 \mathrm{~mm}$ & $19.68 \mathrm{MPa}$ & 11.0 & 32.1 \\
\hline
\end{tabular}




\subsection{Pseudocode}

The pseudocode code presented in Figure 9 described the object manipulation process of the designed gripping system. The pseudocode described the operation of the gripping control procedure and the grip states throughout the pick-and-place procedure. The pseudocode initially identified the location of the object through a known position data input. The robot then identified the position of grasping. The grip contact and intensity was derived from a tactile force feedback loop. The micro-controller calculated and communicated the correct grip force required in the gripping phase. Finally, the object was released at the identified end location. The loop repeated until all object assemblies and movements had been completed.

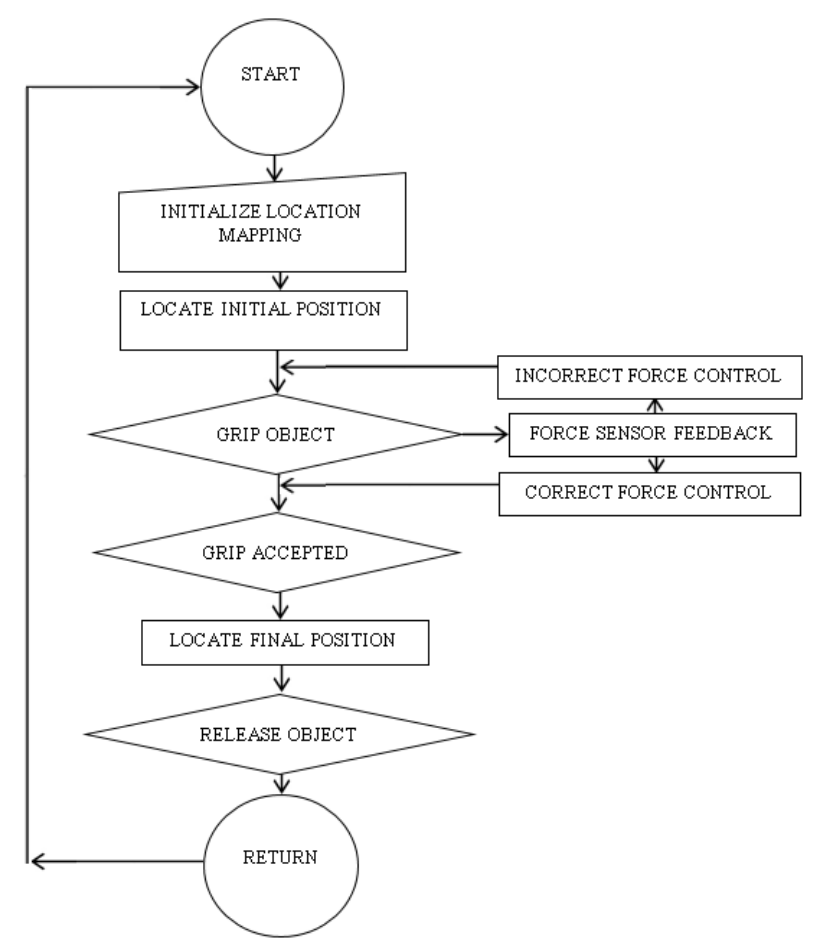

Figure 9: Pseudocode for gripper system

\subsection{Force feedback control}

The proposed sensory system regulated the force measured and the intensity of the force according to the desired force variable. The voltage signal received from force value conversion from the sensor was relayed to the microcontroller, as shown in Figure 10. The signal was transmitted to the gripper and measured against the desired variable. In the event that the new signal was not appropriate compared with the desired variable, a new signal was sent to the microcontroller.

The sensor position and force directions can be seen in Figure 11. The force signal relates to the magnitude of the force contact area between the object and the gripping surface. The measured force should be greater than the friction force between the contact surfaces to reduce the chance of slipping. The force should also not be greater than the force required so as not to compromise the integrity of the object surface condition [16]. 


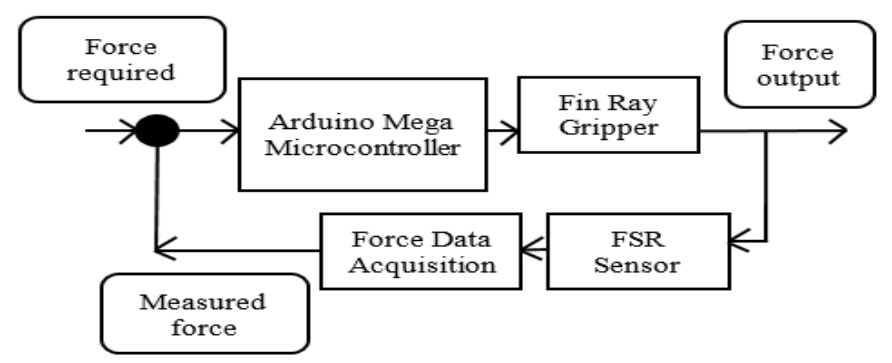

Figure 10: Force sensor feedback loop

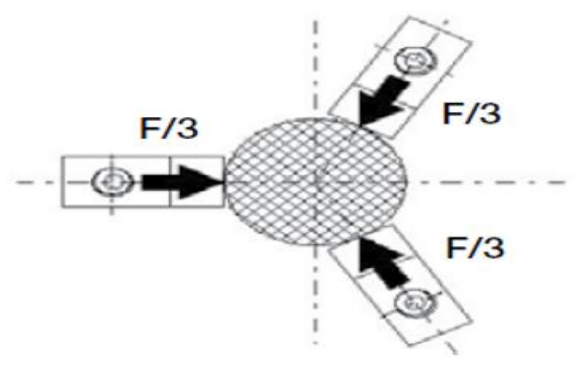

Figure 11: Force and sensor orientation in grip direction [16]

\section{KINEMATIC AND DYNAMIC MODEL DESCRIBING FORCES ACTING ON MODEL}

\subsection{The requirement for kinematic and dynamic control of gripper system}

The mathematical model focused on the flexible gripper and robotic arm sub-systems. The subsystems consisted of a FANUC M10-iA industrial robotic arm and a three-finger and/or a four-finger Fin Ray ${ }^{\circledR}$ gripper. The design incorporates a force feedback system collaborating between the motor actuation of the end-effector and the electronic architecture. The force control criteria can be described theoretically from the output characteristic values of the mathematical model established for the robotic arm.

The dynamic force components manipulating the gripping properties were derived from the acceleration occurrence during a selected pick-and-place movement. The mathematical model was developed from the Denavit-Hartenberg model [17]. The potential performance criteria of the system were established in terms of the gripping force required by the design. The force output ranges were incorporated in selecting the actuation specification of the gripper. Additionally, a force feedback system should be incorporated to dynamically manipulate the load required from the grasping actuation. The mathematical model, therefore, expresses a potential dynamic model for force characteristics required for a closed robotic system for flexible gripper integration.

\subsection{Denavit-Hartenberg model for FANUC M-10iA}

The convention proposed was the Denavit-Hartenberg model, a widely used convention for the forward kinematics of robotic systems to determine the position of the end-effector. The DH-matrix condenses a six-by-six matrix that contains three rotational and three translational displacements into a four-by-four matrix containing two rotational and two translational displacements, shown in equation (1). The links of the serial robots are represented as the link length $a_{i}$ and the link twist angle $a_{i}$. The twist angle parameter designates the angle of the twist between $i$ and $i-1$. The joints are additionally represented by the offset of the link $d_{i}$ and the angular revolute of the joint $\theta_{i}$. The four parameters are used in the $\mathrm{DH}$-matrix, shown in equation (2) .

$$
A_{i}=\left[\operatorname{Rot}_{z, \theta_{i}}\right]\left[\operatorname{Trans}_{x, d_{i}}\right]\left[\operatorname{Trans}_{x, a_{i}}\right]\left[\operatorname{Rot}_{x, \alpha_{i}}\right]
$$




$$
A_{i}=\left[\begin{array}{cccc}
c_{\theta_{i}} & -s_{\theta_{i}} c_{\alpha_{i}} & s_{\theta_{i}} s_{\alpha_{i}} & a_{i} c_{\theta_{i}} \\
s_{\theta_{i}} & c_{\theta_{i}} c_{\alpha_{i}} & -c_{\theta_{i}} s_{\alpha_{i}} & a_{i} s_{\theta_{i}} \\
0 & s_{\alpha_{i}} & c_{\alpha_{i}} & d_{i} \\
0 & 0 & 0 & 1
\end{array}\right]
$$

The system to be described was the FANUC $M$-10ia robotic arm. The selected robotic arm consists of six degrees of freedom [18], therefore requiring six DH matrices, one for each joint. The degrees of freedom are shown in Figure 12. The $\mathrm{DH}$ model determines the operational dimensions and the work envelope of the specified robotic arm.

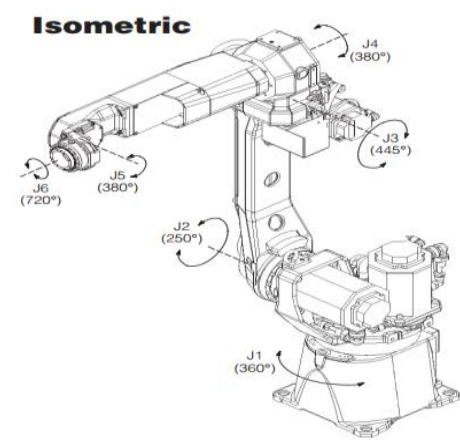

Figure 12: The joint orientation of the M-10iA [18]

The robotic arm can be represented in terms of the reference frames shown in Figure 13. The free body diagram describes the geometric dimensions and the elements for rotation in terms of the alignment of the joints [19]. The free body diagram enables the correct selection of the orientation of joints.

1) Z-axis is in the direction of the joint axis.

2) $X$-axis is perpendicular to both $\mathrm{Zn}$ and $\mathrm{Zn}-1$.

3) $Y$-axis follows the right-hand rule.

4) The $\mathrm{Xn}$ axis must intersect the $\mathrm{Zn}-1$ axis.

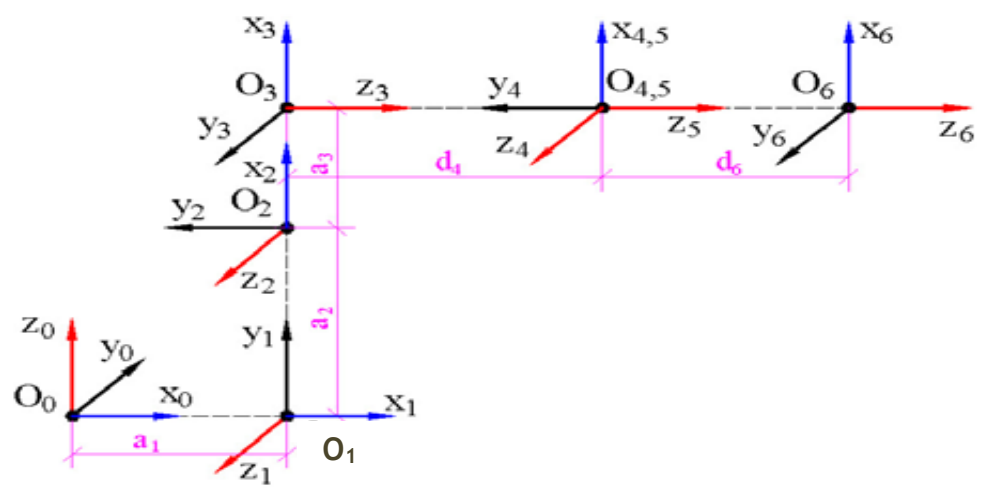

Figure 13: Coordinate reference frames for $M-10 i A$ robotic arm [19]

The joint arm links of the robotic arm are numbered 1 to 6 , from the base to the end-effector of the arm. The origin reference frame from the base is denoted as $\mathrm{O}_{0}$ on a free body diagram. The position of joints 4,5 , and 6 affects the rotation of the tool axis and not the location of the tool [20]. The offset of joint 4 is shifted to joint 5 , due to the singularities it creates on the DH-matrix entries. The input geometries are shown in Table 5.

Each joint has a corresponding homogeneous transformation matrix. The transformation matrices are described in equation (3) for each of the joint sets. The sets of matrices are multiplied by one another to describe the position matrix of the end-effector in equation (4). The homogeneous matrix $T_{n}^{0}$ describes the displacements in the translation plane of the $\mathrm{x}, \mathrm{y}$, and $\mathrm{z}$ axes. The translation 
displacements are expressed as $P_{x}, P_{y}$, and $P_{z}$ as described by equation (5). The position magnitudes are generated to calculate the acceleration properties of the system.

Table 5: Geometric inputs for the DH model

\begin{tabular}{|c|c|c|c|c|}
\hline $\mathbf{T}_{\mathbf{i}}$ & $\mathbf{a}_{\mathbf{i}}$ & $\mathbf{a}_{\mathbf{i}}$ & $\theta_{\mathbf{i}}$ & $\mathbf{d}_{\mathbf{i}}$ \\
\hline $\mathbf{1}$ & $\frac{\pi}{2}$ & $\mathrm{a}_{1}$ & $\theta_{1+\frac{\pi}{2}}$ & 0 \\
\hline $\mathbf{2}$ & 0 & $\mathrm{a}_{2}$ & $\theta_{2}$ & 0 \\
\hline $\mathbf{3}$ & $\frac{\pi}{2}$ & $\mathrm{a}_{3}$ & $\theta_{3}$ & 0 \\
\hline $\mathbf{4}$ & $-\frac{\pi}{2}$ & 0 & $\theta_{4}$ & $\mathrm{~d}_{4}$ \\
\hline $\mathbf{5}$ & $\frac{\pi}{2}$ & 0 & $\theta_{5}$ & 0 \\
\hline $\mathbf{6}$ & 0 & 0 & $\theta_{6}$ & $\mathrm{~d}_{6}$ \\
\hline
\end{tabular}

$$
\begin{gathered}
T_{1}=\left[\begin{array}{cccc}
c_{1} & 0 & s_{1} & a_{1} \cdot c_{1} \\
s_{1} & 0 & -c_{1} & a_{1} \cdot s_{1} \\
0 & 1 & 0 & 0 \\
0 & 0 & 0 & s_{1}
\end{array}\right] T_{2}=\left[\begin{array}{cccc}
c_{2} & -s_{2} & 0 & a_{2} \cdot c_{2} \\
s_{2} & c_{2} & 0 & a_{2} \cdot s_{2} \\
0 & 0 & 1 & 0 \\
0 & 0 & 0 & 1
\end{array}\right] T_{3}=\left[\begin{array}{cccc}
c_{3} & 0 & s_{3} & a_{3} \cdot c_{3} \\
s_{3} & 0 & -c_{3} & a_{3} \cdot s_{3} \\
0 & 1 & 0 & 0 \\
0 & 0 & 0 & 1
\end{array}\right] \\
T_{4}=\left[\begin{array}{cccc}
c_{4} & 0 & -s_{4} & 0 \\
s_{4} & 0 & c_{4} & 0 \\
0 & -1 & 0 & d_{4} \\
0 & 0 & 0 & 1
\end{array}\right] T_{5}=\left[\begin{array}{cccc}
c_{5} & 0 & s_{5} & 0 \\
s_{5} & 0 & -c_{5} & 0 \\
0 & 1 & 0 & 0 \\
0 & 0 & 0 & 1
\end{array}\right] \quad T_{6}=\left[\begin{array}{cccc}
c_{6} & -s_{6} & 0 & 0 \\
s_{6} & c_{6} & 0 & 0 \\
0 & 0 & 1 & d_{6} \\
0 & 0 & 0 & 1
\end{array}\right]
\end{gathered}
$$

where:

$\mathrm{a}_{1}=150 \mathrm{~mm}$

$\mathrm{a}_{2}=600 \mathrm{~mm}$

$\mathrm{a}_{3}=200 \mathrm{~mm}$

$\mathrm{d}_{4}=640 \mathrm{~mm}$

$\mathrm{d}_{6}=370 \mathrm{~mm}$

$c_{i}=\cos \left(\theta_{i}\right)$

$\mathrm{s}_{\mathrm{i}}=\sin \left(\theta_{\mathrm{i}}\right)$

$$
\begin{aligned}
T_{n}^{0} & =T \cdot T_{2}^{1} \cdot T_{3}^{2} \cdot T_{4}^{3} \cdot T_{5}^{4} \cdot T_{6}^{5} \\
T_{n}^{0} & =\left[\begin{array}{cccc}
s_{x} & n_{x} & a_{x} & P_{x} \\
s_{y} & n_{y} & a_{y} & P_{y} \\
s_{z} & n_{z} & a_{z} & P_{z} \\
0 & 0 & 0 & 1
\end{array}\right]
\end{aligned}
$$

\subsection{Lagrangian force model}

The values generated by equation (5) are introduced into equation (6). Equation (6) describes the combined Jacobian matrix for the acceleration components of an object in motion [21]. The equation is derived from differentiating the combined Jacobian vector matrix for displacement to generate a velocity Jacobian matrix. The velocity Jacobian matrix is differentiated to generate an acceleration Jacobian matrix.

where:

$$
\ddot{X}=J(q) \ddot{q}+\left[\frac{d}{d t} j(q)\right] \dot{q}
$$

Ẍ: Acceleration vector matrix.

$\mathrm{J}$ : Displacement Jacobean matrix.

j: Velocity Jacobean matrix.

$q$ : Displacement vector.

$\dot{\mathrm{q}}$ : Velocity vector.

q̈: Acceleration vector.

The applicable forces can be described by means of a Lagrangian torque model, describing the force components of a moving object, as shown in Figure 14. The mathematical model describes the inertia component $\mathrm{A}$, the Coriolis component $\mathrm{C}$, the centripetal component $\mathrm{B}$, and the gravitational component $\mathrm{G}$ [22]. The acceleration and velocity vectors from equation (6) are used to compute the force vectors in equation (7). 


$$
A(q)[\ddot{q}]+B(q)[\dot{q} q]+C(q)[\ddot{q}]+G(q)=\tau
$$

where:

q: Vector of joint angles.

$A(q)$ : Symmetric, bounded, positive definite inertia matrix.

$\mathrm{C}(q)$ : Coriolis forces.

$B(q)$ : Centripetal forces.

$G(q)$ : Gravitational force.

t: Vector of actuator torques.

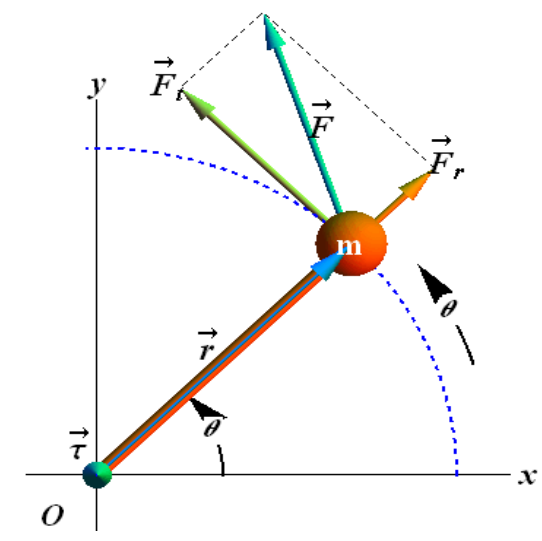

Figure 14: Force attributes of a moving object [22]

\section{TESTING FOR GRIPPER CONFORMITY}

\subsection{Static holding mass test}

A mass holding test was executed on the gripper system. The gripper was preloaded with $1630 \mathrm{~g}$, and increments of $100 \mathrm{~g}$ were added until failure occurred due to slippage. The maximum loading mass range was $2435 \mathrm{~g}$ as a selected criterion. The maximum mass holding range for geometry is shown in Figure 15 for the three-finger and four-finger grippers. The experiment was repeated 15 times to determine repeatability. The experiment was repeated for Geometries 1, 2, 3 and 4. Additionally, the experiment was performed on the three-finger and four-finger grippers. The repeatability of the gripping procedure resembles the probability of the gripper system being able perfectly to grip the maximum mass range. The slipping of the object during the experiment was due to a variety of factors, including a variation in grip force, slippage, eccentric grip, static coefficient irregularities, and surface characteristics.

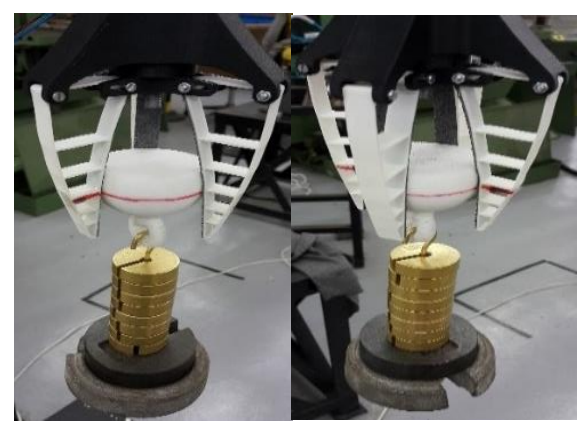

Figure 15: Mass holding test of three-finger and four-finger grippers

The results from the mass holding test for the three-finger and four-finger grippers are shown in Table 6 and Table 7 respectively. The average mass range and the repeatability rounded off performance for the three-finger gripper were 2.2-2.4 kg and 89-97 per cent respectively. The average mass range and the repeatability rounded off performance for the four-finger gripper were 2.3-2.5 kg and 83-99 per cent respectively. The ideal repeatability range would be 98 per cent; nonetheless, factoring in slippage conditions, a realistic repeatability would be 90 per cent. 
Table 6: Mass holding test for three-finger gripper

\begin{tabular}{|c|c|c|}
\hline Geometry & Average mass & Repeatability \\
\hline $\mathbf{1}$ & $2177.05 \mathrm{~g}$ & $89.2 \%$ \\
\hline $\mathbf{2}$ & $2297.99 \mathrm{~g}$ & $93.7 \%$ \\
\hline $\mathbf{3}$ & $2338.34 \mathrm{~g}$ & $92.4 \%$ \\
\hline $\mathbf{4}$ & $2418.87 \mathrm{~g}$ & $97.3 \%$ \\
\hline
\end{tabular}

Table 7: Mass holding test for four-finger gripper

\begin{tabular}{|c|c|c|}
\hline Geometry & Average mass & Repeatability \\
\hline $\mathbf{1}$ & $2344.80 \mathrm{~g}$ & $93.4 \%$ \\
\hline $\mathbf{2}$ & $2418.89 \mathrm{~g}$ & $96.9 \%$ \\
\hline $\mathbf{3}$ & $2398.64 \mathrm{~g}$ & $95.9 \%$ \\
\hline $\mathbf{4}$ & $2459.15 \mathrm{~g}$ & $98.6 \%$ \\
\hline
\end{tabular}

\subsection{Dynamic holding force test}

Dynamic testing was performed on the three-finger and four-finger gripper system. A spherical specimen weighing $320 \mathrm{~g}$ was grasped. The specimen needed to be concentric to enable direct contact with all the sensors. The testing was applied to Geometries 1, 2, 3 and 4, as shown in Figure 16. The specimen was grasped and manipulated according to a set path plan for the robotic arm. Voltage signal data was recorded according to time. The signal values were transmitted at a transferral rate of $10 \mathrm{~Hz}$. The resulting data is shown in Figure 17 as a voltage versus time graph. The voltage signal represents the force applied to the object through the gripper fingers. The graph shows a steady signal, with the addition of a slight incline confirming self-conformity through dynamic movement. The experiment was repeated five times for accuracy. The dynamic performance of the three-finger and four-finger grippers is shown in Table 8 and Table 9 respectively.
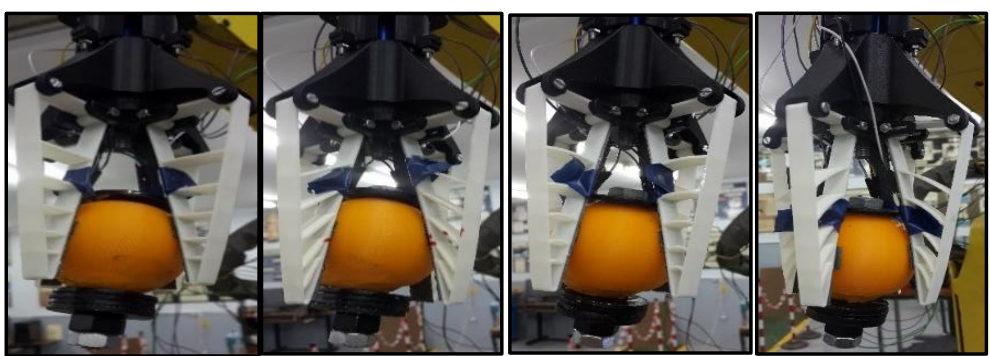

Figure 16: Dynamic test for four-finger gripper: Geometries 1, 2, 3 and 4

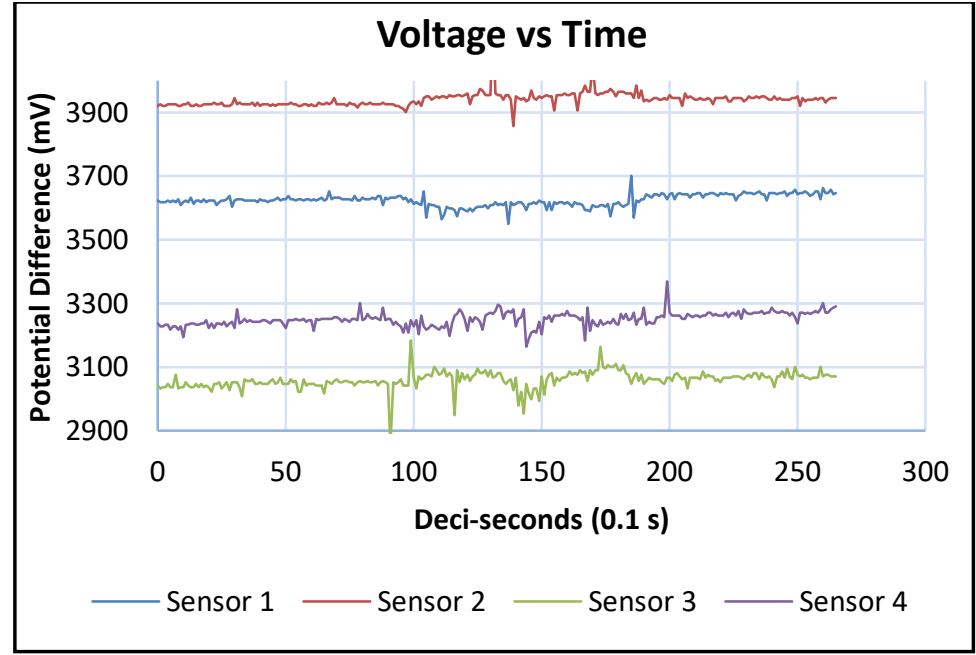

Figure 17: Voltage versus time graph for four-finger gripper: Geometry 1. (see online version for colour) 
Table 8: Three-finger dynamic gripper performance

\begin{tabular}{|c|c|c|}
\hline Configuration & Dynamic loading (g) & Estimated grip force required (g) \\
\hline Geometry 1 & 320 & 1660 \\
\hline Geometry 2 & 320 & 1607 \\
\hline Geometry 3 & 320 & 1687 \\
\hline Geometry 4 & 320 & 1257 \\
\hline
\end{tabular}

Table 9: Four-finger dynamic gripper performance

\begin{tabular}{|c|c|c|}
\hline Configuration & Dynamic loading (g) & Estimated grip force required (g) \\
\hline Geometry 1 & 320 & 1504 \\
\hline Geometry 2 & 320 & 1420 \\
\hline Geometry 3 & 320 & 1479 \\
\hline Geometry 4 & 320 & 1146 \\
\hline
\end{tabular}

\subsection{Dynamic and static visual test for miscellaneous parts}

Dynamic testing was performed to evaluate the gripping conformity through visual confirmation, as shown in Figure 18. Various mass and geometric specimens were gripped, and a dynamic movement representing a pick-and-place procedure was applied. The experiment was repeated five times each for the three-finger and four-finger grippers, incorporating Geometries 1, 2, 3 and 4. The results showed complete conformity and stable gripping throughout the experiment in all configurations.
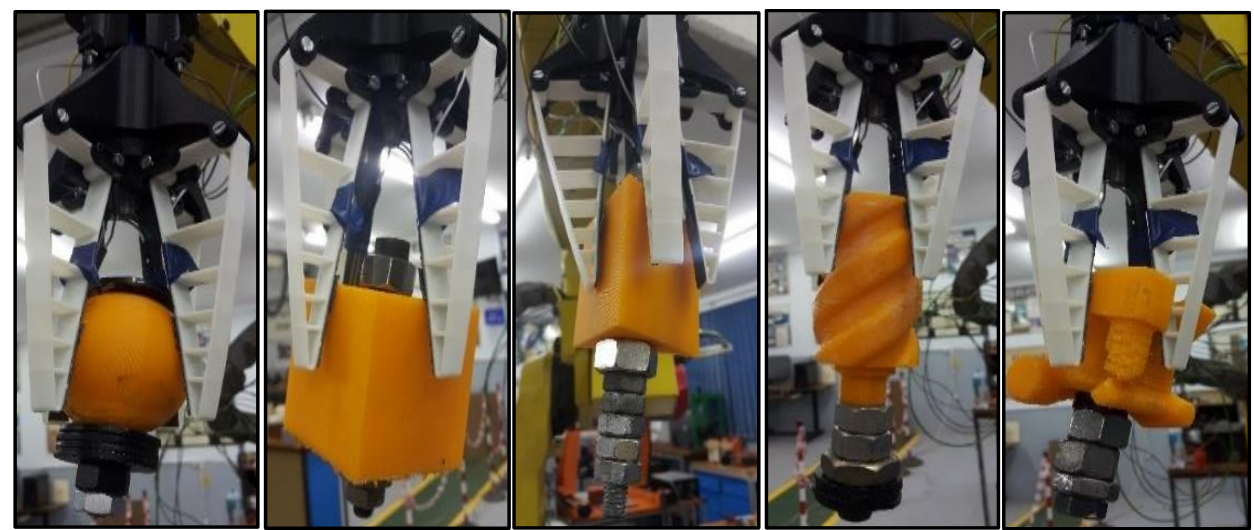

Figure 18: Visual dynamic and static testing of the four-finger gripper for Geometry 1.

\section{CONCLUSION}

The biologically inspired gripper was analysed in terms of its conformity properties. The gripper appendages were designed according to the Fin Ray Effect ${ }^{\circledR}$, and the ribs structure was altered accordingly for increased flexibility. The geometric rib structures were simulated for conformity in terms of displacement. The design considerations were taken into account, and a finite element analysis (FEA) proved that the altered rib constructs affected the conformity properties of the appendages in respect of deflection, as shown in Table 3 and Table 4. The operational force components for the object being gripped in the Fin Ray Effect ${ }^{\circledR}$ design were described using a Lagrangian model. The position values from modelling the robotic arm through a DH homogeneous transformation matrix were able to be used to determine the velocity and acceleration components for the Lagrangian model. A Jacobian matrix described the model to determine the acceleration components. The three-finger and four-finger gripper system, including the four geometries, were tested in a mass holding test. The static testing showed the increased repeatability and holding values of the modified rib structures, as shown in Table 6 and Table 7. The repeatability of the gripper system was attained through the experimentation process using the ideal and real repeatability ranges from the ISO specifications. Dynamic testing produced an better performance for the modified rib structures, as shown in Table 8 and Table 9. 
The modified rib structures proved to have better gripping characteristics than those of the traditional Fin Ray Effect $^{\circledR}$ (Geometry 1) rib configuration, as shown in Table 10. That qualitative comparison table outlines how the performance increased through the modification of gripper finger geometries. The most improved performance criterion was determined to be Geometry 4, which consisted of a circular and skewed geometric construct. High stress zones were avoided by including rounded structures and angled geometries to reduce high stress flow along the material.

Table 10: Qualitative comparison of rib structure geometries for the three-finger and fourfinger grippers

\begin{tabular}{|c|l|l|l|l|l|}
\hline $\begin{array}{l}\text { Gripping } \\
\text { geometry }\end{array}$ & $\begin{array}{l}\text { Conformity } \\
\text { deflection } \\
\text { (FEA) }\end{array}$ & Repeatability & $\begin{array}{l}\text { Maximum static } \\
\text { loading }\end{array}$ & $\begin{array}{l}\text { Estimated } \\
\text { required grip } \\
\text { force }\end{array}$ & $\begin{array}{l}\text { Varied } \\
\text { shape } \\
\text { holding }\end{array}$ \\
\hline $\mathbf{1}$ & Baseline & Baseline & Baseline & Baseline & Baseline \\
\hline $\mathbf{2}$ & $\begin{array}{l}\text { Highest } \\
\text { improvement }\end{array}$ & Improved & Improved & Improved & Similar \\
\hline $\mathbf{3}$ & Improved & Improved & Improved & Improved & Similar \\
\hline $\mathbf{4}$ & Improved & $\begin{array}{l}\text { Highest } \\
\text { improvement }\end{array}$ & $\begin{array}{l}\text { Highest } \\
\text { improvement }\end{array}$ & $\begin{array}{l}\text { Highest } \\
\text { improvement }\end{array}$ & Similar \\
\hline
\end{tabular}

\section{ACKNOWLEDGEMENTS}

The authors wish to thank the Blue Sky Research Grant under grant number 91339. In addition, acknowledgement is given to the National Research Foundation (NRF) for its grant towards this research. The opinions expressed and conclusions arrived at are those of the authors, and are not necessarily to be attributed to the NRF.

The authors' special thanks are extended to the staff of UKZN for the opportunity to present their work.

\section{REFERENCES}

[1] Dymond, F.S.D. 2009. Conceptual design of fixtureless reconfigurable automated assembly system. MSC Eng Thesis. Stellenbosch: Stellenbosch University.

[2] Grenier-Lafond, O. 2014. Robotic material handling case study - Robotiq adaptive gripper. RobotIQ, 26 August. [Online]. Available: http://blog.robotiq.com/bid/72187/ Robotic-Material-Handling-Case-StudyRobotiq-Adaptive-Gripper. [Accessed 1 November 2016].

[3] Bostelman, R. and Falco, J. 2012. Survey of industrial manipulation technologies for autonomous assembly applications. Gaithersburg, Maryland: National Institute of Standards and Technology.

[4] Kärcher, N., Moerdijk, M.M. and Schrof, S. 2015. FlexShapeGripper. Esslingen: FESTO AG \& Co. KG.

[5] FESTO. 2014. MultiChoiceGripper. Esslingen: FESTO.

[6] Empire Robotics. 2015. Versball Gripper: Research kit model CV2-1 - Product manual. Boston: Empire Robotics.

[7] Robotiq. 2016. Adaptive gripper. Quebec City: Robotiq.

[8] Crooks, W., Vukasin, G., O'Sullivan, M., Messner, W. and Rogers. C. 2016. Fin Ray Effect inspired soft robotic gripper: From the RoboSoft grand challenge toward optimization, Frontiers in Robotics and Al, 3(70), pp. 1-9.

[9] International Organization of Standards. 1998. ISO 9283:1998 Manipulating industrial robots Performance criteria and related test methods. Geneva: ISO.

[10] Chan, L.L., Tracy, M.F., Guttormson, J. and Savik, K. 2016. Description of peripheral muscle strength measurement and correlates of muscle weakness in patients receiving prolonged mechanical ventilatory support, Am J Crit Care, 24(6), pp. e91-e98.

[11] Petruzella, F. 1996. Industrial electronics. Singapore: McGraw Hill.

[12] Technical Committee ISO/TC 184. 2012. International Standard ISO 14539. Geneva: ISO.

[13] Prešeren, J., Avguštin, D. and Mravlje, T. 2005. Guidelines for the design of robotic gripping systems. Ljubljana: University of Ljubljana.

[14] Tharayil, V., Babu, E., Cherussery, A.A. and Joy, J.P. 2017. Design, fabrication and analysis of three fingered fin gripper for KUKA KR`R900 robot, SSRG International Journal of Mechanical Engineering, Special number, pp. 42-44.

[15] Brischetto, S., Ferro, C.G., Maggiore, P. and Torre, R. 2017. Compression tests of ABS specimens for UAV components produced via the FDM technique, Technologies, 5(20), pp. 1-25.

[16] Intelligent Actuator. 2016. Selection guide (gripping force). Atlanta: Intelligent Actuator.

[17] Yang, C., Ma, H. and Fu, M. 2016. Robot kinematics and dynamics modelling. Singapore: Springer publishing. 
[18] FANUC Robotics. 2008. M-10iA series. Lutho: FANUC Robotics America.

[19] Constantin, D., Lupoae, M., Baciu, C. and Buliga, D.-I. 2015. Forward kinematics of an industrial robot. Vienna: Institute for Natural Sciences and Engineering.

[20] Bouzgou, K. and Ahmed-Foitih, Z. 2014. Geometric modelling and singularity of 6 DOF Fanuc 200IC robot, IEEE Fourth edition of the International Conference on the Innovative Computing Technology, Luton, pp 208-214.

[21] Sadun, A.S., Jalani, J. and Sukor, J.A. 2016. Force sensing resistor (FSR): A brief overview and the lowcost sensor for active compliance control, SPIEFirst International Workshop on Pattern Recognition, Tokyo, Vol. 10011, pp 1001112.

[22] Yang, C., Ma, H. and Fu, M. 2016. Advanced technologies in modern robotic applications. Singapore: Springer. 